\title{
LED light sources improved the essential oil components and antioxidant activity of two genotypes of lemon balm (Melissa officinalis L.)
}

Tayebeh Ahmadi ${ }^{1}$, Leila Shabani ${ }^{1,2^{*}}$ (1) and Mohammad R. Sabzalian ${ }^{3}$

\begin{abstract}
Background: Nowadays, light-emitting diodes (LEDs) as a new lighting technology, have been emerged as an alternative source of light for plants due to their wavelength specificity, the narrow width of their bands, small size, solid structure, long lifetime, and low heat generation. Here we investigated the effect of different LED light sources on the essential oil components and antioxidant activity of Melissa officinalis. Two genotypes of lemon balm (Ilam and Isfahan) were subjected to four artificial light treatments, including white, red, blue, red + blue LEDs, and greenhouse light as natural lighting.

Results: The LED lights significantly increased shoot fresh and dry weights and leaf number in the two genotypes as compared to greenhouse condition. The results showed that the content and composition of essential oil in the two genotypes were variable under different light treatments and the total amount of compounds in the llam genotype was higher than the other genotype. The results of analysis of the essential oil by GC/MS indicated that the highest amount of monoterpenes in the genotypes was related to citronellal under red + blue LED lamps (15.3 and 17.2\% in Ilam and Isfahan genotypes, respectively) but blue, white, and greenhouse condition had the most effect on sesquiterpenes content in both genotypes. The results showed that the observed variation between the two genotypes in the essentials oil composition was related to the relative percentage of the constituents and not to the appearance or lack of a specific component. Red + blue lighting also provided the highest radical scavenging activity in both genotypes (80.77 and 82.09\% for Ilam and Isfahan genotypes, respectively). Based on principal component analyses (PCA), three main groups were identified regarding genotypes and all light treatments.
\end{abstract}

Conclusions: Overall, results indicated that the essentials oil composition of two genotypes of lemon balm was affected both qualitatively and quantitatively by different LED light sources; hence, LED lights might be used to improve monoterpenes, sesquiterpenes, and antioxidant activity in the selected genotypes.

Keywords: Antioxidant activity, Essential oil, Light-emitting diodes (LEDs), Melissa officinalis

\section{Introduction}

Melissa officinalis (lemon balm) is native to the north of Iran, western Asia, southern Europe, and northern Africa (Noorul Basar and Zaman 2013). This medicinal plant belongs to the family Lamiaceae that whose scented

\footnotetext{
*Correspondence: shabani-I@sku.ac.ir; Ishabani@gmail.com

${ }^{1}$ Department of Plant Science, Faculty of Science, Shahrekord University,

Shahrekord, Iran

Full list of author information is available at the end of the article
}

leaves have been consumed as a spice for salads and cold drinks, decoction, infusion, or directly used in food for decades. Several studies have shown antioxidant, hypoglycemic, hypolipidemic, anti-cancer, anti-depressant, sedative, and anti-inflammatory effects, in addition to known effects of this plant for digestive problems, rheumatism, or headache (Weidner et al. 2015; Birdane et al. 2007). Generally, the essential oil extracted from the aerial parts of lemon balm $(0.02-0.8 \%$, with the main components being citral and citronellal) is one of the classes 
of compounds that are useful for food, nutrition, pharmacological and cosmetic applications, and antioxidant activities of the plant (Mazzanti et al. 2008).

Many secondary metabolites, such as flavonoids, essential oils, and phenolic acids are produced in response to environmental stresses (Weitzel and Peterson 2010). light, As an important environmental factor, is an essential source of energy for the photosynthesis of a plant, as well as an important message for plant growth and development. Nowadays, new technologies such as light-emitting diodes (LEDs) lamps provide better growth of plants by emitting an appropriate intensity and wavelength of light as an alternative source for sunlight (Sabzalian et al. 2014). LEDs can also stimulate the generation of secondary metabolites and essential oils in plants (Ghaffari et al. 2019; Tohidi et al. 2019). Blue LED light made the highest amount of essential oil in basil leaves (Amaki et al. 2011) and Perovskia atriplicifolia (Gaffari et al. 2019). The highest thymol content was observed in Thymus migricus under blue LED light (Tohidi et al. 2019). Red LED light significantly increased lutein and glycosinolate in Brassica oleracea leaf (Lefsrud et al. 2008) and phenylacetaldehyde in Petunia hybrid flower (Colquhoun et al. 2013). Sabzalian and co-workers (2014) recorded a four-fold increase in essential oil production of Mentha longifolia under red + blue LED light. The positive effect of blue, white, and green LED lights was equally reported by Jung et al. (2013) on the antioxidant activity of rice leaves. Johkan and his colleagues (2010) also stated that the antioxidant activity of lettuce seedlings treated with blue LEDs was higher than that of red and fluorescent lights. Additionally, the variability among plant genotypes influences the quantity and quality of secondary metabolites, which leads to great differences in secondary metabolite synthesis (Gahler et al. 2003). Several studies have revealed that the essential oil components and yield can vary with plant genotypes (Rajendra et al. 2016; Gholami-Zali and Ehsanzadeh 2018). However, little data have been published about the variation in the essential oil composition between the lemon balm genotypes.

Today, the global strategy in the production of medicinal and aromatic plants is to improve the quantity, quality, and health of their essential oils, and due to the emergence of adverse effects of chemicals used in agriculture, such as fertilizers and pesticides, the tendency to use approaches that are healthier and more environmentally friendly is on the rise. In this regard, the use of LED lamps technology while providing plants with better growth and production, also helps to better protect the environment. The goal of this study was to investigate the effects of four light wavelengths of LED lamps on two genotypes of lemon balm (Ilam and Isfahan), regarding growth, antioxidant activity, and essential oil constituents.

\section{Material and methods Plant material}

The plant material of this study was Melissa officinalis plants that were collected from fields in Eyvan city of Ilam province (voucher no. 4897, with geographical coordinates $\left.33^{\circ} 53^{\prime} \mathrm{N} 46^{\circ} 11^{\prime} \mathrm{E}\right)$ and Isfahan city of Isfahan province (voucher no. 4898, with geographical coordinates $\left.32^{\circ} 38^{\prime} 41^{\prime \prime} \mathrm{N} 51^{\circ} 40^{\prime} 03^{\prime \prime} \mathrm{E}\right)$. Three rhizomes were planted in each pot (15 cm diameter) containing 3:1 loam-sandy soil (30 pots for two genotypes).

\section{System of light and experimental condition}

The experiment was conducted in two separate environments including greenhouse and LED incubators according to a completely randomized design. On March 11, 2016, 24 pots (12 from each genotype) were incubated in four growth cabinets (i.e. 3 pots from each genotype per each cabinet). Each cabinet's lighting system contained red $(660 \mathrm{~nm})$, blue $(460 \mathrm{~nm})$, white $(380-760 \mathrm{~nm})$ and red + blue (70:30 ratio) LED lamps with a light intensity of $300 \mu \mathrm{mol} \cdot \mathrm{m}^{-2} \cdot \mathrm{s}^{-1}$, with a $16 \mathrm{~h}$ illumination and $8 \mathrm{~h}$ darkness and at $25 \pm 2{ }^{\circ} \mathrm{C}$. On the same date, 6 pots ( 3 pots from each genotype) were kept in the research greenhouse of Isfahan University of Technology, in similar conditions under natural sunlight. All pots were irrigated daily with water and once a week with 1/2 Hoagland solution. After 7 weeks, on April 29, plants were transferred to the laboratory for analysis.

\section{Assessment of growth parameters}

First, the samples were washed with distilled water and their excess moisture was removed with filter paper. The fresh weight of plant shoots was determined in grams after cutting the roots from the crown. To calculate the dry weight, each sample, after being placed in paper bags, was dried in an oven at $65^{\circ} \mathrm{C}$ for $48 \mathrm{~h}$ and then weighed in grams. The leaves were counted separately in each pot.

\section{Extraction of essential oil}

Seven weeks after exposure to LED lighting, $10 \mathrm{~g}$ of dry leaves from each light treatment was used for essential oil extraction. The dried and ground leaves were submitted to $150 \mathrm{ml}$ water distillation using a Clevenger apparatus. The sample of oils was extracted in triplicate. The essential oil was extracted for $6 \mathrm{~h}$ at $70-80^{\circ} \mathrm{C}$ temperature. The volatile fraction collected was kept in sealed glass vials and stored at $4{ }^{\circ} \mathrm{C}$ before GC-MS analysis. The essential oil content (\%) was calculated as follow: 
Essential oil content $(\%)=$ Mass of isolated essential oil $(\mathrm{g}) /$ dried shoot $(\mathrm{g}) \times 100$

\section{Gas chromatography-mass spectrometry (GC-MS)}

Gas chromatography-mass spectroscopy (GC-MS) analysis for the essential oil composition was carried out on a Hewlett-Packard 5890 gas chromatograph (HewlettPackard, EquipNet, Inc. 50 Hudson Road Canton, MA 02021 USA) coupled to an HP 5970 mass-selective detector (MSD) (Hewlett-Packard, EquipNet, Inc. 50 Hudson Road Canton, MA 02021 USA) using a fused silica ultra-performance cross-linked methyl silicone column (50 mm length, $0.2 \mathrm{~mm}$ inner diameter, film thickness $25 \mu \mathrm{m})$. Temperature programming was done from 100 to $250{ }^{\circ} \mathrm{C}$ at a rate of $4{ }^{\circ} \mathrm{C} \mathrm{min}^{-1}$. Helium was used as the carrier gas at a $1 \mathrm{ml} \mathrm{min}^{-1}$ flow rate. Ionization energy at $70 \mathrm{eV}$ and $250{ }^{\circ} \mathrm{C}$ temperature were ordered for the ion source (Li et al. 2009). Identification of the essential oil compounds was based on the comparison of their spectral fragmentation with the data reported in the NIST 08 (National Institute of Standards and Technology), Mass Spectra Libraries, and those reported in Davies 1990 (Additional files 1, 2, 3, 4). Retention indices (RI) were determined with $\mathrm{C} 5-\mathrm{C} 26$ alkane standards as reference. They were confirmed by a nonpolar HP-5MS column through comparison of their mass spectra against those recorded in the NIST 08, Willey 275.L (ChemStation data system), and those reported in the literature (Davies, 1990).

\section{Determination of antioxidant activity}

\section{2,2-diphenyl-1-picrylhydrazyl radical scavenging activity}

The radical scavenging activity (RSA) of the extracts was monitored using the stable free radical 2,2-diphenyl1-picrylhydrazyl (DPPH) following the method described by Kulisica et al. (2004). Extract solutions (1 ml) were mixed with $1 \mathrm{ml}$ of a freshly prepared DPPH solution (0.1 $\mathrm{mM}$ in methanol) and $3 \mathrm{ml}$ of $96 \%$ ethanol. The mixture was shaken vigorously and left to stand at room temperature for $30 \mathrm{~min}$ in dark (until stable absorbance values were obtained). The reduction in the DPPH radical content was measured by monitoring the decrease in absorption at $517 \mathrm{~nm}$. RSA of the extracts was calculated by the following formula:

\section{Statistical analysis}

Since the cultivation of plants was in greenhouse and 4 incubators in the laboratory, considered as an experiment in separate environments, so for the measured factors, the significance of variation was assessed using the combined analysis of data using SAS statistical program (ver. 8; SAS Institute Inc., Cray, NC, USA) and the least significant differences method was used for mean comparisons. Identification of interrelationships between the genotypes of Melissa officinalis subjected to LED lighting with measured traits was done using principal component analysis (PCA).

\section{Results \\ Growth parameters}

The effect of different light sources and genotypes on growth parameters was significant (Table 1). Table 2 showed that the highest shoot fresh and dry weights and leaf number were observed under the red+blue LED light source in plants of both genotypes.

\section{Essential oil content and constituents}

The essential oil content of two genotypes of $M$. officinalis was not significantly affected by different LED light sources when compared to the greenhouse condition (in the range of $0.27-0.32 \%$, data not shown). However, the effect of different light sources and genotypes on major compounds of lemon balm essential oil was significant (Table 1). A total of thirty-eight compounds were identified using GC-MS analysis (Table 3). A considerable difference was observed in the concentration of essential oil constituents in both genotypes of $M$. officinalis grown under various light sources (Table 3 ). In plants of Ilam genotype, $ß$-cubebene and citronellal had the lowest and highest amounts among all of the identified constituents under red and red + blue LEDs, respectively with 0.6 and $15.3 \%$, but in the other genotype, the lowest amount of essential oil compounds belonged to bicyclo[2.2.1] heptan-2-one, $ß$-ionone, and eugenol in plants that were subjected to red, blue, and red + blue LEDs (0.8\%). Among essential oil compounds, citronellal had the highest con-

$\%$ Radical scavenging activity $=($ control OD $($ optical density $)-$ sample OD/control OD $) \times 100$.

Methanol (80\%) and DPPH solution $(0.1 \mathrm{mM}, 5 \mathrm{ml})$ were used separately as a blank and control sample, respectively. The test also was done in triplicate. tent (17.2\%) under red + blue LED lights in the Isfahan genotype. 


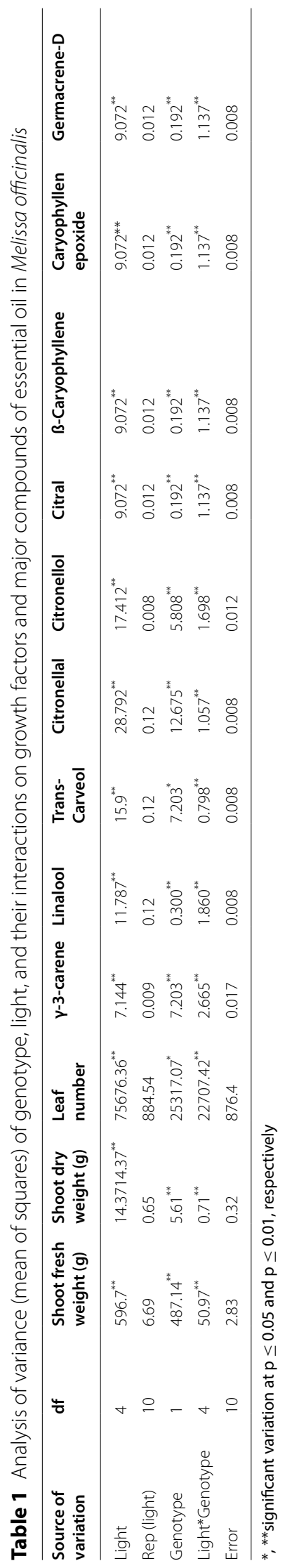


Table 2 Interaction of genotype and light on growth indices in two lemon balm genotypes under different levels of light (Data in the table represent means \pm SE and different letters indicate a significant difference at the probability level of 0.05 based on LSD test)

\begin{tabular}{|c|c|c|c|c|c|c|}
\hline \multirow[t]{2}{*}{ Light/Genotype } & \multicolumn{2}{|c|}{ Shoot fresh weight (g) } & \multicolumn{2}{|c|}{ Shoot dry weight (g) } & \multicolumn{2}{|c|}{ Leaf number } \\
\hline & Ilam & Isfahan & Ilam & Isfahan & Ilam & Isfahan \\
\hline White LED & $29.65 \pm 2.55^{b}$ & $25.46 \pm 0.04^{c}$ & $4.7 \pm 0.2^{c}$ & $3.74 \pm 0.1^{\mathrm{e}}$ & $387 \pm 17^{d}$ & $317 \pm 17^{\epsilon}$ \\
\hline Red + Blue LED & $44.32 \pm 1.1^{\mathrm{a}}$ & $45.11 \pm 0.66^{\mathrm{a}}$ & $7.17 \pm 0.4^{\mathrm{a}}$ & $7.74 \pm 0.2^{\mathrm{a}}$ & $646 \pm 20^{\mathrm{a}}$ & $688 \pm 15^{\circ}$ \\
\hline Red LED & $32.6 \pm 0.5^{b}$ & $42.26 \pm 2.54^{\mathrm{a}}$ & $5.53 \pm 0.1^{c}$ & $6.4 \pm 0.3^{b}$ & $556 \pm 50^{b}$ & $544 \pm 6^{b}$ \\
\hline Blue LED & $30 \pm 3.97^{b}$ & $22.25 \pm 0.12^{d}$ & $4.70 \pm 0.1^{d}$ & $3.39 \pm 0.04^{f}$ & $253 \pm 22^{e}$ & $330 \pm 49$ \\
\hline Greenhouse & $22.82 \pm 1.04^{d}$ & $18.4 \pm 0.63^{e}$ & $3.54 \pm 0.4^{e}$ & $3.54 \pm 0.1^{\mathrm{e}}$ & $469 \pm 12^{c}$ & $213 \pm 40^{f}$ \\
\hline
\end{tabular}

\section{Monoterpenes content under various light treatments in two genotypes of $M$. officinalis}

The number of identified monoterpenes in the two genotypes of lemon balm was 21 compounds. The amount of these compounds was different under various light treatments. In the Ilam genotype, the highest amount of monoterpenes was observed in incubators with white, red + blue, and red LEDs, but in the Isfahan genotype, these compounds were higher under blue LED and greenhouse condition. The red + blue LED light treatment in both genotypes produced the highest amount of monoterpene compounds compared to the greenhouse condition (Table 3).

In the Ilam genotype, monoterpene compounds ranged from $0.9 \%$ for myrcene under red +blue LED to $15.3 \%$ for citronellal under the same light treatment (Table 3). Under LED light treatments, monoterpenes such as myrcene, alpha-phellandrene, para cymene, eucalyptol, $\gamma$-terpinene, linalool, cis-sabinene, trans-carveol, citronellal, citral, thymol, carveol, and carveol acetate were more affected than greenhouse condition. In this genotype, myrcene $(0.9 \%)$ and para cymene $(1 \%)$ had the lowest content among identified monoterpenes, regardless of light treatment. In this genotype, the red + blue LED treatment resulted in the highest amount of major essential oils namely citronellal (15.3\%), trans-carveol (10.2\%), linalool $(8.9 \%)$, and citral (8.2\%) compared to the other lights.

The range of monoterpene composition in the Isfahan genotype changed from $1 \%$ for thymol under white LED light to citronellal with $17.2 \%$ under red + blue LED light (Table 3). Myrcene, limonene, eucalyptol (1.2\%), and thymol (1\%) had the lowest values among known monoterpenes, regardless of light treatments. Alphapinene, myrcene, $\gamma$-3-carene, limonene, eucalyptol, linalool, cis-sabinene, $\beta$-thujone, trans-carveole, citronellal, citral, thymol, and carveol had the most contents in plants grown in incubators with LED lamps compared to the greenhouse condition. Among light treatments, red + blue LED light had the highest contribution to increasing the amount of major essential oils including citronellal (17.2\%), trans-carveole (11.1\%), citral (9.1\%), and linalool (8.9\%).

\section{Sesquiterpenes content under various light treatments in two genotypes of $M$. officinalis}

According to the results shown in Table 3, the number of sesquiterpene compounds in lemon balm genotypes was also significantly affected by light treatments. In Ilam and Isfahan genotypes, the highest amount of these compounds were obtained under blue and white LEDs and greenhouse conditions, respectively. In the Ilam genotype, LED light treatments increased the level of sesquiterpenes such as $\beta$-caryophyllene, $\alpha$-humulene, germacrene- $D, \beta$-ionone, and $\beta$-cubebene but decreased the amount of caryophyllene epoxide, calamenene, and $\alpha$-muurolene compared to the greenhouse condition. In contrast, in the Isfahan genotype, only $\alpha$-humulene, ß-ionoe, and germacrene-D levels were higher in most LED treatments compared to greenhouse conditions. The reduction in the amount of $\beta$-caryophyllene, caryophyllene epoxide, and calamenene treated with LED light was significantly higher than the greenhouse condition. In plants of two genotypes, caryophyllene epoxide, germacrene-D, and $B$-caryophyllene were sesquiterpene compounds with the highest amount, respectively, regardless of light treatments.

\section{Radical scavenging activity analysis}

Results of the analysis of variance of free radical scavenging activity (RSA or antioxidant activity) showed that there was no significant difference between the two genotypes in terms of this activity, while the effect of different lights on RSA was significant $(p \leq 0.01)$ (Table 1). In both genotypes, the highest RSA\% was obtained for plants grown under red+blue LED light (80.77 and $82.09 \%$ for Ilam and Isfahan genotypes, respectively), and the lowest was for plants grown under the greenhouse condition (34.29 and $25.67 \%$ for Ilam and Isfahan genotypes, respectively) (Fig. 1). 


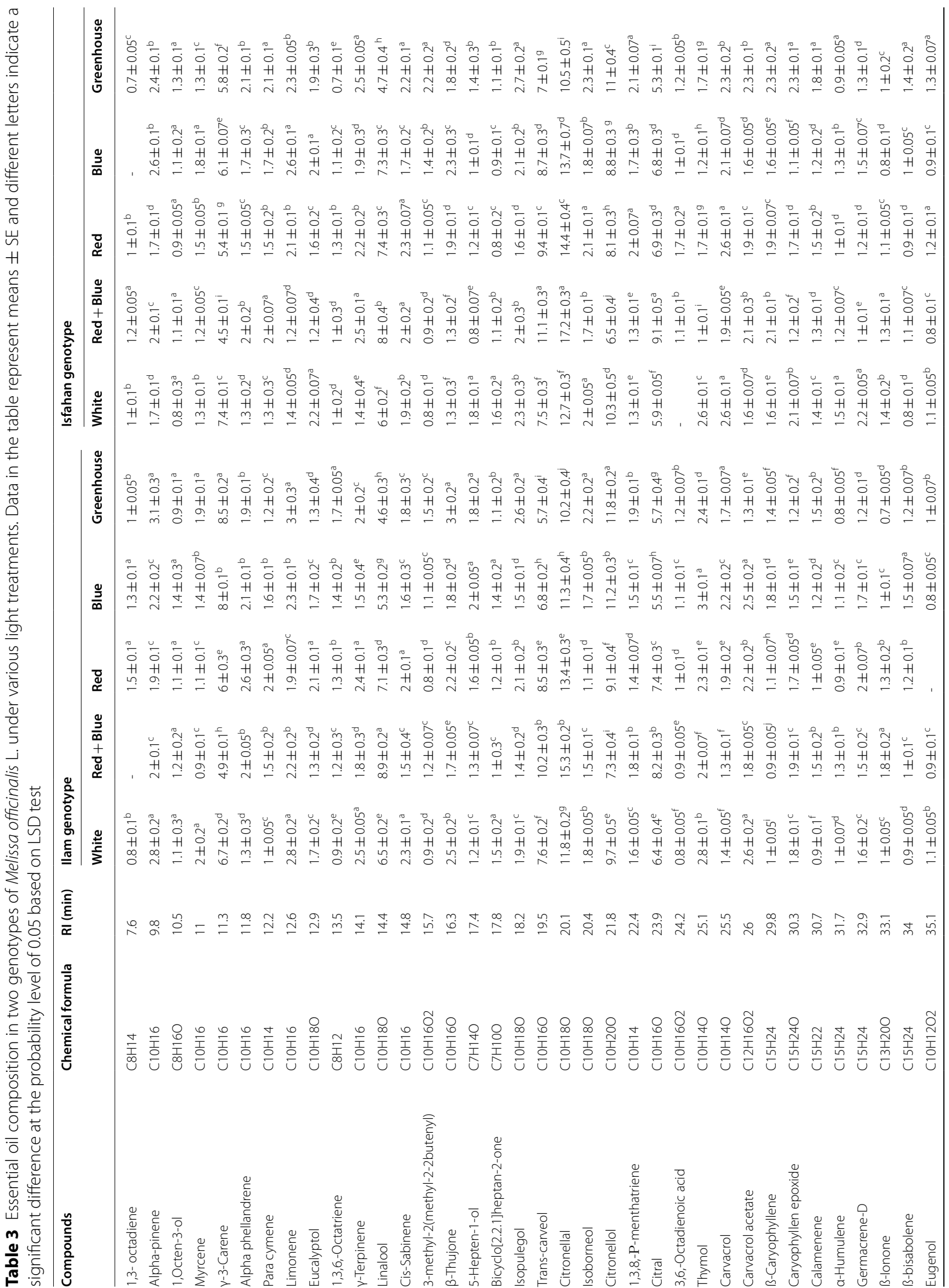




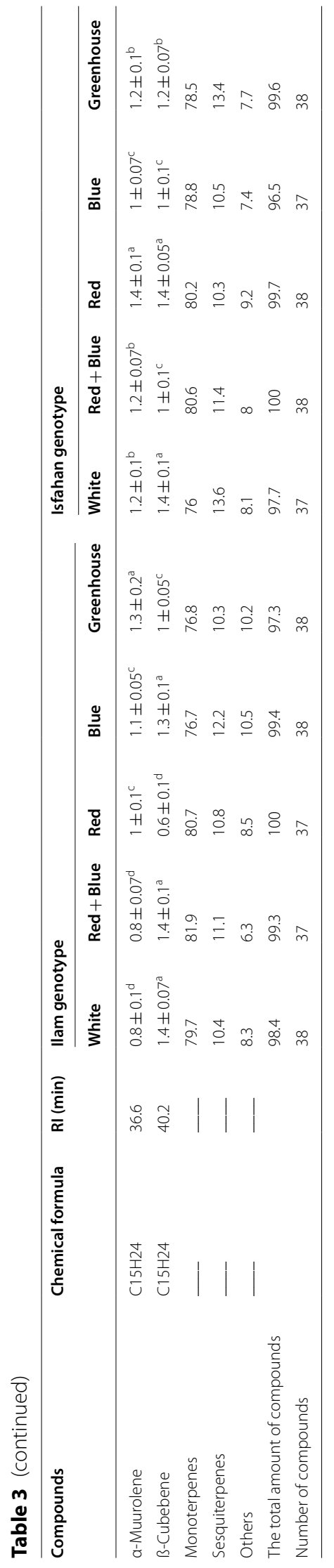




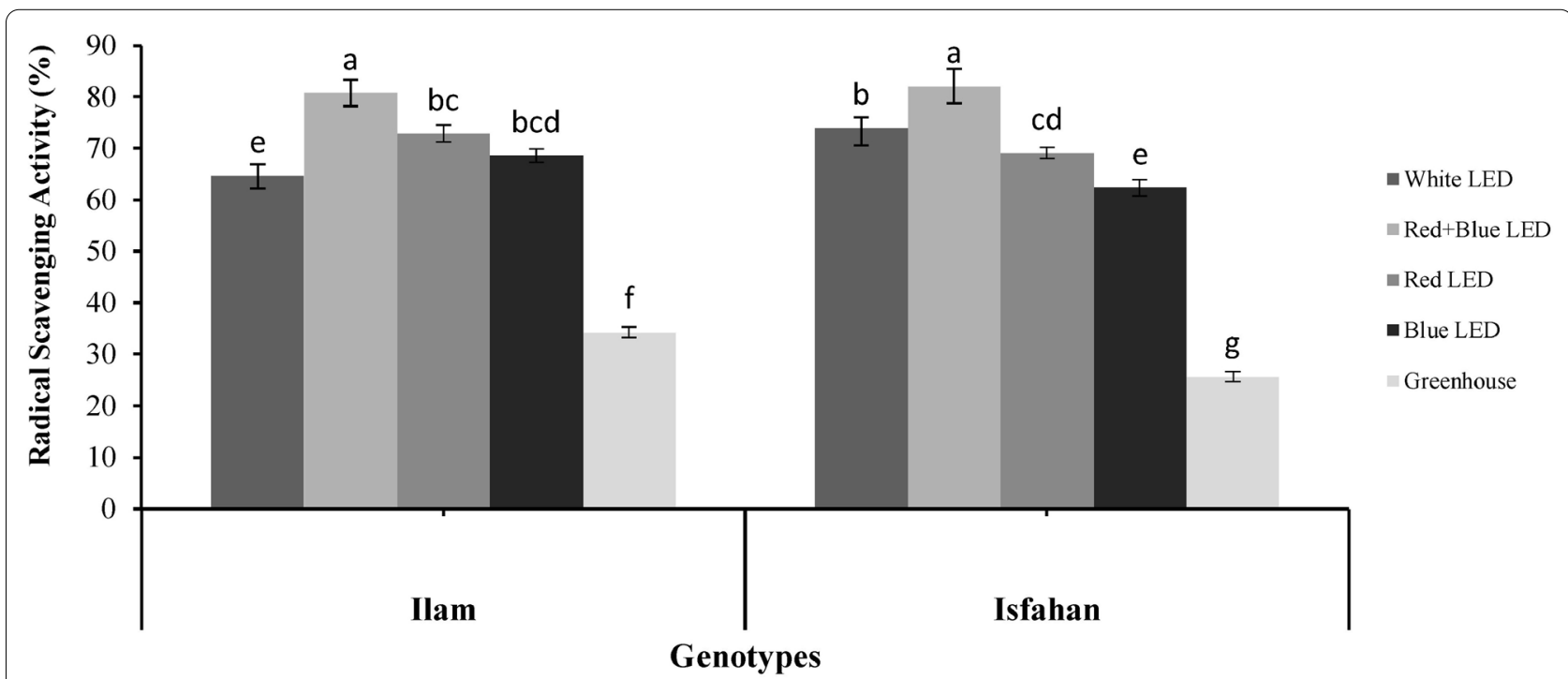

Fig. 1 Interaction of genotype* ${ }^{*}$ ight on free radical scavenging activity in leaves of two genotypes of Melissa officinalis affected by different levels of light (non-identical letters indicate significant difference at 0.01 probability level of LSD test)

\section{Principal component analysis}

Principal component analysis (PCA) was used to identify the relationship between growth parameters and essential oil components, antioxidant activity, and different wavelengths applied on two genotypes of lemon balm (Fig. 2). The results of PCA analysis identified three main groups and these results also indicated that the first and second groups altogether accounted for $78.39 \%$ of the total variation. The first PC (PC1) and the second $\mathrm{PC}$ (PC2) revealed 64.61 and $13.77 \%$ of the total variation, respectively. The plants grown under LED light sources were completely separated based on the growth parameters, essential oil constituents, and antioxidant activity, from those grown in the greenhouse condition. In terms of caryophyllene, only plants of the Isfahan genotype that were grown in incubators containing red and blue LEDs were similar to greenhouse light. In the other group, Ilam genotype that was under red + blue and red LEDs, and Isfahan genotype grown under red+blue, red and blue LEDs, there were the highest levels of main monoterpene compounds such as citronellal, trans-carveol, linalool, and citral and the highest antioxidant activity plus shoot fresh and dry weights. The third group, the Ilam genotype grown under white and blue LEDs, and Isfahan genotypes with white LEDs also had the same and the highest amount of monoterpene compounds such as citronellol and $\gamma-3$ carene and sesquiterpene compounds such as caryophyllene epoxide and germacrene-D.

\section{Discussion}

The effect of different light sources on growth parameters In the present study, under red+blue LEDs, the highest values of growth parameters were observed. An increase in fresh and dry weights, leaf area, and chlorophyll content in lettuce plants in studies conducted by Kim et al. (2004), Johkan et al. (2010), and Yorio et al. (2001) showed that the highest amount of these indicators can be seen under the combination of red and blue lights. Also, the combination of red + blue lights increased fresh and dry weights by 3 times compared to the combination of blue and far-red light. It seemed that the combination of red and blue lights increased plant growth by increasing the amount of pure photosynthesis because the red+blue light energy distribution corresponded to the absorption spectrum of chlorophyll (Wang et al. 2007). On the other hand, the intensity of photons from LED lamps is higher than that of other light sources, which is another mechanism of the positive effect of LED lights to improve plant growth indices (Yorio et al. 2001).

\section{The effect of different light sources on essential oil content} and constituents

It is very important to study the change in the amount of essential oil of medicinal plants because it is related to the change in their nutritional, medicinal, and antioxidant properties. Scientists believed that the chemical composition of essential oil and production of secondary metabolites are related to the physiology of the plant, 


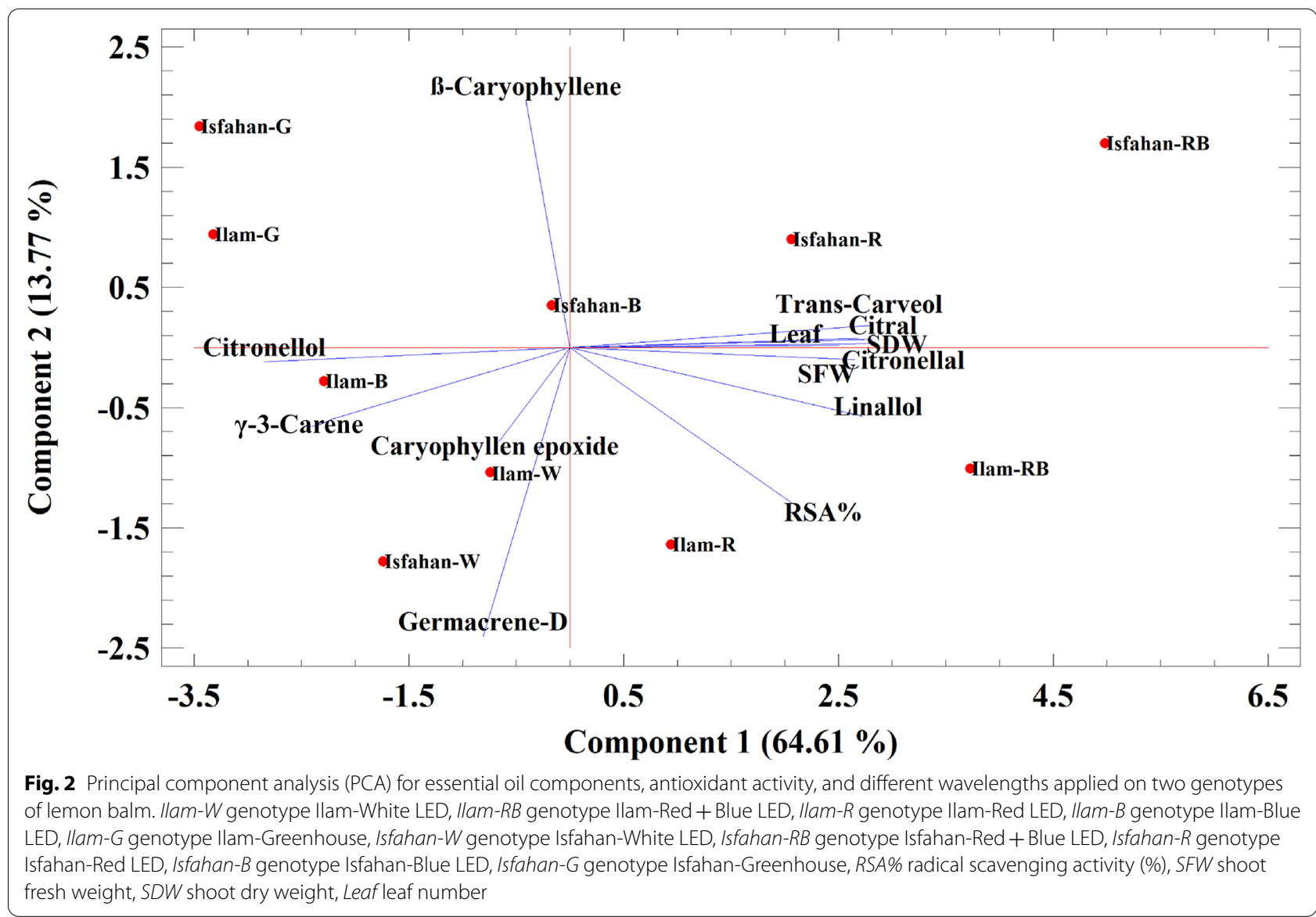

developmental stage, plant species, and various treatments such as various light sources (Yu et al. 2005; Fernandes et al. 2013; Mashkani et al. 2018). Content and composition of plant's essential oil are influenced by many factors, including environmental conditions (Fernandes et al. 2013; İzg1 et al. 2017), light period, light intensity (Shafiee-Hajiabad et al. 2016), and light spectrum (Li and Kubota 2009). The light spectrum acts a significant function in controlling morphology, growth processes, and photosynthesis activities in plants (Wang et al. 2016). Besides, most plant species can promote acclimation systems to cope with different lights, including changing their content of essential oil, which could be one of the mechanisms that plants respond to stress (Zhang et al. 2003). Ivanitskikh and Tarakanov (2014) stated that changes in the light spectrum can be utilized for the biosynthesis of material in plants including essential oils. The light intensity can also alter essential oil production by the stimulation of photo-sensitive enzymes required for the mevalonic acid pathway. Thus, irradiance can directly affect the generation of essential oils, or indirectly, through the increase in plant biomass (Pegoraro et al. 2010). Increasing the number of leaves and trichomes (Fernandes et al. 2013), the effect of light on the expression of genes affecting essential oil synthesis (Urbonavičiūtè et al. 2008), and increasing the number of intermediates involved in essential oil biosynthesis such as IPP (Selmar and Kirinwächter 2013) are some other mechanisms that show the role of natural light in increasing essential oils. Recently, there is a global trend in arid regions of the world including Iran to use greenhouses and indoor facilities instead of the field for growing medicinal species due to the shortage in irrigation water (Mesgaran and Azadi, 2018). In these conditions, LEDs can be used as a supplementary light or sole source of light for boosting photosynthesis and increasing metabolites accumulation. As Darko et al. (2014) stated, LED lights can mimic the effects of natural light, and therefore, it is not unreasonable to expect that LED lights can also increase these compounds by mechanisms similar to what is interpreted about the effect of natural light on increasing the amount of essential oils in plants.

In the study by Batista et al. (2016) on three chemotypes of Lippia alba, they demonstrated that the differences in the composition of essential oil were more influenced by the chemotype than light treatments (LED 
and fluorescent) applied. They and Viccini et al. (2014) stated that this difference between genotypes and chemotypes could be depended on the content of plant DNA.

The content and composition of essential oils in two genotypes studied in the present work were variable under different light treatments and the total amount of compounds in the Ilam genotype was higher than that in the other genotype. However, the observed variation between two genotypes in the essentials oil composition was related to the relative percentage of the constituents and not to the appearance or lack of a specific component. Light quality and its intensity influenced the production of secondary metabolites and essential oils with changes in physiological and morphological properties of plants (Briskin et al. 2001). Light affects the number and morphology of leaves and essential oil storage structures such as trichrome, causing changes in the amount and chemical composition of essential oil in plants (Fernandes et al. 2013).

The results of this study tend to indicate that LED lights have a positive effect on the essential oil content. In the present study, in plants of the Ilam genotype, all LED lights had a greater effect on essential oil content than plants grown under greenhouse conditions but in the Isfahan genotype, only the effect of red + blue and red LEDs treatments was higher than greenhouse conditions. Treatments of red and red + blue LEDs on Ilam and Isfahan genotypes resulted in the greatest essential oil contents. Other studies have suggested the positive effect of LED light on increasing the essential oil content in Mentha species, green vegetables (such as parsley, onion, lettuce, and...), and Brassica oleracea (Sabzalian et al. 2014; Žukauskas et al. 2011; Lefsrud et al. 2008).

\section{The effect of different light sources on monoterpenes}

The highest amount of monoterpenes in both genotypes were observed under red + blue LEDs. citronellal, trans-carveol, linalool, and citral had the highest levels of monoterpenes in both genotypes. The chemical composition of lemon balm essential oil (that is $0.02-0.3 \%$ of DW) had been previously investigated. The main combination was citronellal (2-40\%) and citral (10-30\%) with B-caryophyllene, germacrene- $D$, ocimene, and citronellol (Schultze et al. 1989; Adzet et al. 1992; Kreis and Mosandl 1994; Moradkhani et al. 2010). Citronellal, as one of the major components in the essential oil of lemon balm, is a monoterpene aldehyde (Chung et al. 2010). In the present study, citronellal percentage varied from 10.2 to $17.2 \%$, and the highest amount $(17.2 \%)$ was detected in plants of both genotypes grown in incubators containing red + blue LEDs. In many studies, citral after citronellal was the most commonly reported composition of lemon balm essential oil, but as was seen in the present study, the highest essential oil content after citronellal was citronellol with a varied range of $6.5-11.8 \%$. In the present study, citral after citronellal, citronellol, and trans-carveol had the highest amount of essential oil in two genotypes under different light treatments.

Light quality can change the composition of essential oils in medicinal plants (Amaki et al. 2011). In a study by Batista et al. (2016), different qualities of light caused a change in the pattern of essential oil in Lippia alba. These researchers showed changes in the number of monoterpenes such as eucalyptol and linalool in two $L$. alba chemotypes under LED and fluorescent lamps. Noguchi and Amaki (2016) and Nguyen and Saleh (2019) reported an increase in monoterpenes such as alpha-pinene, betapinene, limonene and carvone in mint plants under red LED light.

According to the findings of the present study, it was found that in the two genotypes of lemon balm, light treatments play an effective role in changing the content of monoterpenes. Since most of the essential oil components of lemon balm in this study were monoterpenes, it is concluded that the quality and property of essential oil will probably change significantly. Ghaffari et al. (2019) and Tohidi et al. (2019) reached the same results with the current study about the increase in the content of monoterpenes under LED lamps. In the present study, red + blue LED light was the major contributor to the increase in monoterpenes. On the contrary, in studies by Ghaffari et al. (2019) and Tohidi et al. (2019), blue light played this role. Therefore, this difference reflects the different effects of LED light on the essential oil of different plants.

It is well known that the increase in the production of secondary metabolites is related to plant growth conditions such as temperature, light regime, stress, nutrition source, etc. (Selmar and Kirinwächter 2013). If the light energy that is absorbed by the photosynthetic apparatus exceeds the energy required for $\mathrm{CO}_{2}$ fixation, large amounts of this energy ultimately led to the production of secondary metabolites according to the energy dissipation mechanism proposed by Selmar and Kirinwächter (2013). In the present study, since the intensity of light in LEDs $\left(300 \mu \mathrm{mol} . \mathrm{m}^{-2} . \mathrm{s}^{-1}\right)$ is continuously higher than greenhouse conditions, these light sources, especially red + blue LED light, can be considered as severe light stress and probably increased monoterpenes according to the mechanism described above. Recently, researchers have found that terpenoids biosynthesis in addition to the mevalonic acid (MVA) pathway is made from primary metabolites through another pathway called methylerythritol phosphate (MEP), which is present in plastids and chloroplasts (Lichtenthaler et al. 1999). Therefore, it can be stated that under the treatment of 
LED lights, especially under red + blue LED light, due to the matching of these wavelengths to the absorption peak of photosynthetic pigments, LEDs increased photosynthesis and production of photosynthetic intermediates, especially IPP (isopentenyl diphosphate). This process may have resulted in the activation of the MEP pathway more and more and produced high levels of these terpenoids.

\section{The effect of different light sources on sesquiterpenes}

Different light sources changed the content of sesquiterpenes of two genotypes of lemon balm. As in Jalal et al.s study (2015), in this study, the main sesquiterpene of lemon balm was $ß$-caryophyllene epoxide (11\%) that its vector was correlated with white LED light environment in both genotypes (Fig. 2). In the study of Kittler et al. (2018) B-caryophyllene, germacrene-D, and $\beta$-caryophyllene epoxide constituted the main sesquiterpene compounds of lemon balm genotypes. However, in the study conducted by Chung et al. (2010), caryophyllene $(0.8 \%)$ and farnesene $(0.1 \%)$ were the most common sesquiterpene. So, it can be said that the essential oil composition of species and genotypes of a plant are different under different conditions. $ß$-caryophyllene is a natural bicyclic sesquiterpene that has also been involved in the creation of a spicy taste of black pepper and many essential oils such as Rosmarinus officinalis, Syzygium aromaticum, and Cannabis sativa. This compound has received much attention because of its cyclobutane ring, which is scarce in nature (Taherpour et al. 2012).

Many studies have shown that LED lights induced several metabolic changes in plants, including increased levels of $\beta$-farnesene, germacrene- $D$, and elements in Mexican mint grown under blue light (Noguchi and Amaki 2016). Alvarenga et al. (2015) showed that high light intensities, such as 47 and $69 \mu \mathrm{mol} . \mathrm{m}^{-2} \cdot \mathrm{s}^{-1}$ increased monoterpene compounds content in Achillea millefolium L., but these intensities reduced the number of sesquiterpenes. Sesquiterpenes such as $\beta$-caryophyllene and $B$-cubebene have the highest values at $13 \mu \mathrm{mol} . \mathrm{m}^{-2} \cdot \mathrm{s}^{-1}$ intensity. Blue LED light in Mentha spicata increased $B$-caryophyllene compared to the control condition. The concentration of beta-bourbonene as a sesquiterpene was also higher in mint cultivated under LED light compared to the control condition (Nguyen and Saleh 2019). An increase in trans-caryophyllene and $\alpha$-humulene in two species of Perovskia has also been reported under the white LED light (Ghafari et al. 2019). Tohidi et al.s (2019) study showed an increase in sesquiterpene levels of three species of thyme under red + blue and red LED lights.

\section{The effect of different light sources on radical scavenging} activity

In the present work, red + blue LEDs and then red LED had the greatest effect on increasing RSA in plants of two genotypes of lemon balm particularly in the Ilam genotype (Fig. 2). Synthesis of secondary metabolites in plants is an important part of the defense response to stress. Oxidative stress and reactive oxygen species (ROS) cause extensive damages to plants. Antioxidant systems that show antioxidant capacity in plants including flavonoids, ascorbate, carotenoids, phenolic compounds, and essential oils, protect plants against photo-oxidative damage (Shohael et al. 2006).

In general, in addition to genetic differences between different species, it has been found that beside the quality of light, altitude and temperature are important environmental factors that affect plant composition and characteristics (Gharibi et al., 2015). Li and Kubota (2009) demonstrated the beneficial role of LEDs in improving antioxidant activity in baby leaf lettuce. Also, Samuoliene et al. (2012) reported that LED supplementation with HPS lamps altered the antioxidant and nutritional properties of lettuce due to increased metabolic system activity to protect plants against moderate photo-oxidative stress induced by the use of LEDs. Žukauskas et al. (2011) showed that complementary red light had an increasing effect on DPPH removal ability in lettuce, but the antioxidant ability of rice leaves in response to blue LED light was higher than that in red LED light (Jung et al., 2013). Also, in a study by Wojciechowska et al. (2015), $100 \%$ red LED exposure did not increase DPPH removal power compared to controls. In the present study, it was observed that the red+blue LED light treatment produced the highest amount of major monoterpene components such as citronellal, trans-carveol, citronellol, linalool, and citral together with the highest RSA\% in two genotypes of lemon balm. Therefore, it can be stated that the antioxidant capacity of these two genotypes under light treatments is directly related to the essential oil components, especially monoterpenes. Confirming this result, researchers have shown that DPPH's scavenging activity is directly related to the levels of phenolic and antioxidant compounds of plants and essential oils (Wojciechowska et al. 2015; Tohidi et al. 2017, 2019).

\section{Conclusion}

In the present study, the effect of different sources of LED light and greenhouse light on two genotypes of lemon balm was measured in terms of growth factors, amount and composition of essential oil, and antioxidant activity. Different light sources had a significant effect on the measured characteristics of the two genotypes, which 
could also alter their medicinal and food properties. In both genotypes, the positive effect of LEDs compared to greenhouse light on the measured properties was quite significant. In both genotypes, red+blue LED produced the highest amount of shoot fresh and dry weights, leaf number, and essential oil monoterpenes, such as citronellal, trans-carveol, linalool, and citral, and the highest amount of antioxidant activity. From the results of the present study, it can be concluded that red + blue LEDs can be introduced as a suitable light treatment for growing and increasing the efficiency of lemon balm plants and probably other medicinal plants. This light treatment has been able to imitate the positive effects of sunlight in increasing the efficiency and performance of lemon balm and has been able to work even better than sunlight. It can be concluded that this light treatment with increasing antioxidant properties could have the best effect on improving the production, and nutritional and pharmaceutical characteristics of lemon balm.

\section{Abbreviations}

LED: Light-emitting diode; RSA: Radical Scavenging Activity; DPPH: 2,2-Diphenyl-1-picrylhydrazyl; MEP: Methylerythritol phosphate; IPP: Isopentenyl diphosphate; PCA: Principal Component Analysis.

\section{Supplementary Information}

The online version contains supplementary material available at https://doi. org/10.1186/s40529-021-00316-7.

Additional file 1: Fig. S1. The chromatogram generated from a red light sample of the llam genotype.

Additional file 2: Fig. S2. The chromatogram generated from a white light sample of the llam genotype.

Additional file 3: Fig. S3. The chromatogram generated from a red+Blue light sample of the Isfahan genotype.

Additional file 4: Fig. S4. The chromatogram generated from a greenhouse light sample of the Isfahan genotype.

\section{Acknowledgements}

The authors are grateful for the grant from Shahrekord University, Iran grant number: 96GRD1M1032.

\section{Authors' contributions}

Conceived and designed the experiments: LS, MRS. Performed the experiments: TA. Analyzed the data: TA, LS, MRS. Wrote the paper:TA, LS. Edited the manuscript: LS, MRS.

\section{Funding:}

Not applicable.

\section{Availability of data and materials Agree.}

\section{Declarations}

Ethics approval and consent to participate Not applicable.

\section{Consent for publication}

Not applicable.

\section{Competing interests}

The authors declare that they have no competing interests.

\section{Author details}

${ }^{1}$ Department of Plant Science, Faculty of Science, Shahrekord University, Shahrekord, Iran. ${ }^{2}$ Research Institute of Biotechnology, Shahrekord University, Shahrekord, Iran. ${ }^{3}$ Department of Agronomy and Plant Breeding, College of Agriculture, Isfahan University of Technology, 84156-83111 Isfahan, Iran.

Received: 19 February 2021 Accepted: 17 May 2021

Published online: 05 June 2021

\section{References}

Adzet T, Ponz R, Wolf E, Schulte E (1992) Content and composition of M. oficinalis oil in relation to leaf position and harvest time. Planta Med 58:562-564

Alvarenga ICA, Pacheco FV, Silva ST, Bertolucci SKV, Pinto JEBP (2015) In vitro culture of Achillea millefolium L.: quality and intensity of light on growth and production of volatiles. Plant Cell Tiss Organ Cult 122:299-308

Amaki W, Yamazaki N, Watanabe H, Ichimura M (2011) Effects of light quality on the growth and essential oil content in sweet basil. Acta Hortic 907:91-94

Batista DS, de Castro KM, de Silva AR, Teixeira ML, Sales ThA, Soares LI, Cradoso MG, Santos MO, Viccini LF, Otoni WC (2016) Light quality affects in vitro growth and essential oil profile in Lippia alba (Verbenaceae). Vitro Cell Dev Biol Plant 52:276-282

Birdane Y, Boyokokuroglu ME, Yavuz H (2007) Anti-inflammatory and antinociceptive effects of Melissa Officinalis L. Rev Méd Vété 158:75-81

Briskin DP, Gawienowski MC (2001) Differential effects of light and nitrogen on production of hypericins and leaf glands in Hypericum perforatum. Plant Physiol 39:1075-1081

Chung MJ, Cho SY, Bhuiyan MJH, Kim KH, Lee SJ (2010) Anti-diabetic effects of lemon balm (Melissa officinalis) essential oil on glucose- and lipid-regulating enzymes in type 2 diabetic mice. Br J Nutr 104:180-188

Colquhoun TA, Schwieterman ML, Gilbert JL, Jaworski EA, Langer KM, Jones CR, Rushing GR, Hunter TM, Olmstead J, Clark DG, Folta KM (2013) Light modulation of volatile organic compounds from petunia flowers and select fruits. Postharvest Biol Technol 86:37-44

Darko E, Heydarizadeh P, Schoefs B, Sabzalian MR (2014) Photosynthesis under artificial light: the shift in primary and secondary metabolism. Philos Trans R Soc Lond Ser B Biol Sci 369:20130243

Davies NW (1990) Gas chromatographic retention indices of monoterpenes and sesquiterpenes on methylsilicon and carbowax 20M phases. J Chromatogr 503:1-24

Fernandes VF, de Almeida LB, Feijó EVdS, Silva DdC, de Oliveira RA, Mielke MS, Costa LCdB (2013) Light intensity on growth, leaf micromorphology and essential oil production of Ocimum gratissimum. Rev Bras Farmacogn 23:419-424

Gahler S, Otto K, Bohm V (2003) Alterations of vitamin C, total phenolics, and antioxidant capacity as affected by processing tomatoes to different products. J Agric Food Chem 51:7962-7968

Ghaffari Z, Rahimmalek M, Sabzalian MR (2019) Variation in the primary and secondary metabolites derived from the isoprenoid pathway in the Perovskia species in response to different wavelengths generated by light emitting diodes (LEDs). Ind Crops Prod 140:111592

Gharibi Sh, Tabatabaei B, Saeidi Gh, Goli A (2015) Effect of drought stress on total phenolic, lipid peroxidation, and antioxidant activity of Achillea species. Appl Biochem Biotech 55:665-678

Gholami-Zali AGh, Ehsanzadeh P (2018) Exogenous proline improves osmoregulation, physiological functions, essential oil, and seed yield of fennel. Ind Crops Prod 111:133-140

Ivanitskikh AS, Tarakanov IG (2014) Effect of light spectral quality on essential oil components in Ocimum basilicum and Salvia officinalis plants. Int J Second Metab 1:19 
İzı MN, Telci I, Elmastaş M (2017) Variation in essential oil composition of coriander (Coriandrum sativum L.) varieties cultivated in two different ecologies. J Essent Oil Res 29:494-498

Jalal Z, Atki YE, Lyoussi B, Abdellaoui A (2015) Phytochemistry of the essential oil of Melissa officinalis L. growing wild in Morocco: Preventive approach against nosocomial infections. Asian Pac J Trop Biomed 5(6):458-461

Johkan M, Shoji K, Goto F, Hashida S, Yoshihara T (2010) Blue light-emitting diode light irradiation of seedlings improves seedling quality and growth after transplanting in red leaf lettuce. HortSci 12:1809-1814

Jung E, Lee S, Lim SH, Ha SH, Liu KH, Lee Ch (2013) Metabolite profiling of the short-term responses of rice leaves (Oryza sativa cv. IImi) cultivated under different LED lights and its correlations with antioxidant activities. Plant Sci 210:61-69

Kim SJ, Hahn EJ, Heo JW, Paek KY (2004) Effects of LEDs on net photosynthetic rate, growth and leaf stomata of Chrysanthemum plantlets in vitro. Sci Hortic 101:143-151

Kittler J, Krüger H, Ulrich D, Zeiger B, Schütze W, Böttcher Ch, Krähmer A, Gudi G, Kästner U, Heuberger H, Marthe F (2018) Content and composition of essential oil and content of rosmarinic acid in lemon balm and balm genotypes (Melissa officinalis). Genet Resour Crop Evol 65:1517-1527

Kreis P, Mosandl A (1994) Chiral compounds of essential oils. Part XVI. Enantioselective multidimensional gas chromatography in authenticy control of balm oil (Melissa oficinalis L.). Flavour Fragr J 9:249-256

Kulisica T, Radonicb A, Kat Kim SJ, Hahn EJ, Heo JW, Paek KY (2004) Use of different methods for testing antioxidative activity of oregano essential oil. Food Chem 85:633-640

Lefsrud MG, Kopsell DA, Sams CE (2008) Irradiance from distinct wavelength light-emitting diodes affect secondary metabolites in kale. HortSci 43:2243-2244

Li Q, Kubota C (2009) Effects of supplemental light quality on growth and phytochemicals of baby leaf lettuce. Environ Exp Bot 67:59-64

Li XM, Tian SL, Pang ZC (2009) Extraction of Cuminum cyminum essential oil by combination technology of organic solvent with low boiling point and system distillation. Food Chem 115:1114-1119

Lichtenthaler HK (1999(The I-deoxy-D-xylulose-5-phosphate pathway of isoprenoid biosynthesis inplants. Annu Rev Plant Physiol Plant Mol Biol 50:47-65.

Mashkani MRD, Larijani K, Mehrafarin A, Badi HN (2018) Changes in the essential oil content and composition of Thymus daenensis Celak. Under different drying methods. Ind Crops Prod 112:389-395

Mazzanti G, Battinelli L, Pompeo C, Serrilli AM, Rossi R, Sauzullo I, Mengoni F, Vullo V (2008) Inhibitory activity of Melissa officinalis L. extract on herpes simplex virus type 2 replication. Nat Prod Res 22:1433-1440

Mesgaran MB, Azadi P (2018) A national adaptation plan for water scarcity in Iran, working paper 6, Stanford Iran 2040 Project, Stanford University.

Moradkhani H, Sargsyan E, Bibak H, Naseri B, Sadat-Hosseini M, Fayazi-Barjin A, Meftahizade H (2010) Melissa officinalis L., a valuable medicine plant: a review. J Med Plants Res 4(25):2753-2759

Nguyen ThL, Saleh MA (2019) Effect of exposure to light emitted diode (LED) lights on essential oil composition of sweet mint plants. J Environ Sci Health 54(5):435-440

Noguchi A, Amaki W (2016) Effects of light quality on the growth and essential oil production in Mexican mint. Acta Hortic 11:187-194

Noorul Basar S, Zaman R (2013) An overview of Badranjboya (Melissa officinalis). Int Res J Biol Sci 2(12):107-109

Pegoraro RL, Falkenberg MdB, Voltolini CH, Santos M, Paulilo MTS (2010) Produção de óleos essenciais em plantas de Mentha x piperita L. var. piperita (Lamiaceae) submetidas a diferentes níveis de luz e nutrição do substrato. Rev Bras Bot 33:631-637

Rajendra PP, Rakshapal S, Rajeswara R, Singh RR, Abhilasha S, Lal RK (2016) Differential response of genotype $x$ environment on phenology, essential oil yield and quality of natural aroma chemicals of five Ocimum species. Ind Crops Prod 87:210-217

Sabzalian MR, Heydarizadeh P, Zahedi M, Boroomand A, Agharokh M, Sahba MR, Schoefs B (2014) High performance of vegetables, flowers and medicinal plants in a red-blue LED incubator for indoor plant production. Agron Sustain Dev 65:127-136

Samuolienè G, Sirtautas R, Brazaityte A, Virsile A, Duchovkis P (2012) Suplementary red-LED lighting and the changes in phytochemical content of two baby leaf lettuce varieties during three seasons. J Food Agric Environ 10:701-706
Schultze W, Zanglein A, Klose R, Kubeczka KH (1989) Lemon balm, thin layer chromatography examination of the essential oil. Dtsch Apothek Ztg 129:155-163

Selmar D, Kirinwächter M (2013) Influencing the product quality by deliberately applying drought stress during the cultivation of medicinal plants. Ind Crop Prod 42:558-566

Shafiee-Hajiabad M, Novak J, Honermeier B (2016) Content and composition of essential oil of four Origanum vulgare L. accessions under reduced and normal light intensity conditions. J Appl Bot Food Qual 89:126-134

Shohael AM, Ali MB, Yu KW, Hahn EJ, Islam R, Paek KY (2006) Effect of light on oxidative stress, secondary metabolites and induction of antioxidant enzymes in Eleutherococcus senticosus somatic embryos in bioreactor. Process Biochem 41:1179-1185

Taherpour A, Maroofi H, Rafie Z, Larijani K (2012) Chemical composition analysis of the essential oil of Melissa officinalis L. from Kurdistan, Iran by HS/ SPME method and calculation of the biophysicochemical coefficients of the components. Nat Prod Res 26(2):152-160

Tohidi B, Rahimmalek M, Arzani A (2017) Essential oil composition, total phenolic, flavonoid contents, and antioxidant activity of Thymus species collected from different regions of Iran. Food Chem 220:153-161

Tohidi B, Rahimmalek M, Arzani A, Sabzalian MR (2019) Thymol, carvacrol, and antioxidant accumulation in Thymus species in response to different light spectra emitted by light-emitting diodes. Food Chem 307:125521

Urbonavičiūtè A, Samuoliene G, Brazaityte A, Ulinskaite R, Jankauskiene J, Duchovskis P, Zukauskas A (2008) The possibility to control the metabolism of green vegetables and sprouts using light emitting diode illumination. Sodinink Darzinink 27:83-92

Viccini LF, Silveira RS, Do Vale AA (2014) Citral and linalool content has been correlated to DNA content in Lippia alba (Mill.) N.E. Brown (Verbenaceae). Ind Crops Prod 59:14-19

Wang CY, Fub CC, Liu YC (2007) Effects of using light-emitting diodes on the cultivation of Spirulina platensis. Biochem Eng J 37:21-25

Wang J, Lu W, Tong Y, Yang Q (2016) Leaf morphology, photosynthetic performance, chlorophyll fluorescence, stomatal development of lettuce (Lactuca sativa L.) exposed to different ratios of red light to blue light. Front Plant Sci 7:1-10

Weidner C, Rousseau M, Plauth A, Wowro SJ, Fischer C, Abdel-Aziz H, Sauer S (2015) Melissa officinalis extract induces apoptosis and inhibits proliferation in colon cancer cells through formation of reactive oxygen species. Phytomed 22(2):262-270

Weitzel C, Petersen M (2010) Enzymes of phenylpropanoid metabolism in the important medicinal plant Melissa officinalis L. Planta 232(3):731-742

Wojciechowska R, Dlugosz-Grochowska O, Kolton A, Żupnik M (2015) Effects of LED supplemental lighting on yield and some qualityparameters of lamb's lettuce grown in two winter cycles. Sci Hortic 187:80-86

Yorio NC, Goins GD, Kagie HR (2001) Improving spinach, radish, and lettuce growth under red light-emitting diodes (LEDs) with blue light supplementation. HortSci 36:380-383

Yu KW, Murthy HN, Hahn EJ, Paek KY (2005) Ginsenoside production by hairy root cultures of Panax ginseng: influence of temperature and light quality. Biochem Eng J 23:53-56

Zhang S, Ma K, Chen L (2003) Response of photosynthetic plasticity of Paeonia suffruticosa to changed light environments. Environ Exp Bot 49:121-133

Žukauskas A, Bliznikas Z, Breviè K, Novičkovas A, Samuolienè G, Urbonavičiūtè A, Brazaitytè A, Jankauskienè J, Duchovskis P (2011) Effect of supplementary pre-harvest LED lighting on the antioxidant properties of lettuce cultivars. Acta Hortic 907:879

\section{Publisher's Note}

Springer Nature remains neutral with regard to jurisdictional claims in published maps and institutional affiliations. 